\title{
Inclusive Education: thinking beyond systems
}

\author{
Anna Robinson-Pant, University of East Anglia
}

\begin{abstract}
$\underline{\text { Abstract }}$
Systems thinking has dominated debates and policy discourses on inclusive education, resulting in an almost exclusive focus on children and formal schooling. Based on the BAICE Presidential Lecture 2019, this paper sets out to consider the limitations of systems theory in framing discussion and research on inclusive education. Alternative theoretical starting points are introduced to analyse vignettes of social and educational inclusion based on workshops facilitated with adults in Ethiopia, Nepal, the UK and the Philippines. In place of systems theory, the paper takes the lenses of culture as performed rather than pre-given, literacy as a social practice and informal learning to explore inclusive education, analysing intercultural and literacy learning in everyday life. The paper argues the need to move beyond systems thinking - particularly closed systems thinking - with its default position of school as providing the solutions. Whilst cultural stereotypes can be challenged in school textbooks and curricula, inclusive education cannot rely on formal institutions alone to initiate changes in social and cultural attitudes held by teachers, students and the wider community.
\end{abstract}

\section{Keywords}

Inclusive education, systems theory, adult literacy, informal learning, intercultural communication

\section{Introduction}

I face a particular challenge in trying to capture the BAICE Presidential Address 2019 in the form of an academic journal article. As will become clear later, this address was a 'performance' in every sense of the word and marked the end-point of a process of working together on a project with colleagues in Ethiopia, Nepal, the UK and the Philippines ${ }^{1}$ to construct a multi-modal text. I have been reflecting since the conference on how to translate what I see as the ' $3 D$ ' version into a ' $2 D$ ' journal article for publication in Compare. This is not just the usual dilemma about how to translate an oral text into a written text - but also about how to recreate the atmosphere at the conference, the element of surprise and excitement we felt as a team trying to subvert and challenge the audience's expectations of a plenary lecture. Recognising the constraints imposed by the conventions of a sole-authored journal article, I have decided to focus here on the argument that I developed. However, I will also provide hyperlinks to the UKFIET conference website where you can find the videoed dramatic performance of each story discussed in this paper, and experience something of the ' $3 \mathrm{D}$ ' version as well.

The theme of this year's UKFIET conference was 'Inclusive Education Systems' and as an adult educator particularly interested in learning outside formal systems, I immediately questioned how linking 'systems' with 'inclusive education' might shape the debates. A key stance put forward at the

\footnotetext{
${ }^{1}$ Although this is a single-authored article, the stories presented within this text as an integral part of the analysis are based on material developed with a team of writers - Chris Millora, Amina Singh, Yukta Bajracharya, Gina Lontoc, Turuwark Warkineh, Abiy Menkir Gizaw - and valuable guidance on script writing provided by Yasmin Sidhwa and Georgia Kaufmann. I have had to shorten these dramatic pieces for this article, but the full versions can be viewed on the hyperlinks.
} 
conference was that to deliver "large scale solutions' ${ }^{2}$ to providing education for all, changes must take place at a systems level. But I wondered what does this approach mean for our thinking about inclusive education? Coming from outside the field of 'inclusive education', I was struck that systems thinking has dominated debates and policy discourses on inclusive education. We tend to start by asking who is inside or outside the system? Why are they excluded by the system? How can they be brought inside? What kind of system change is needed to ensure greater equity and inclusion? Looking at inclusive education policy, I was also interested in the almost exclusive focus on children and formal schooling. Though there was a shift from the language of deficits and handicaps after the watershed moment of the Salamanca statement in 1994 (UNESCO 1994), the dominant discourse is still centred on schools, teachers, children and formal educational programmes. What might 'inclusive education' mean for adults and youth engaged in learning through everyday activities or for communities grappling with the pressing issues affecting their livelihoods - climate change, migration, political conflict?

So this is not just a question about how we can consider those 'outside the system' or how we can improve 'the system'. It is more about exploring alternative ways of looking at 'inclusive education' to generate new questions and approaches. This is a challenge raised by Nidhi Singal (2019:837) who suggested that 'there is increasing onus on researchers to pose more sophisticated questions in relation to inclusive education' and urged greater South-South dialogue on this area. So my main aim here is to explore some different starting points on inclusive education that could lead to new ways for more people - adults and children - to tackle inequality and poverty through learning and education.

'The manner in which an issue is presented will affect the understanding of the issue. Thus the formulation of problematisations will affect our understanding of the problem as well as of the potential solutions that can (or cannot) be used to amend it.' (Bacchi 1999: 680).

I came across this quotation in an article by Magnusson (2019) on 'images of inclusion in the Salamanca Statement'. Bacchi's idea of starting from (and then deconstructing) 'What is the Problem Represented to be?' seems to sum up what I am setting out to do in this paper. My purpose is to look at how we can present and conceptualise the 'problem' differently - to move away from the assumed starting point of 'inclusive education systems'. This is not about rejecting or ignoring 'systems', but about considering the limitations of 'systems thinking' in framing the problem and the questions we ask about inclusive education. In this paper, I will explore some alternative starting points on inclusive education and see where they might lead us.

\section{Systems theory: what's it all about?}

I will begin however with systems thinking - and as part of the overarching theme of the UKFIET conference, it is helpful to see where this concept originated and to understand different approaches to systems theory. In the 1950s, Von Bertalanffy developed a new discipline called 'general systems theory', emerging from his work as a biologist and his frustration at specialisation having led 'to the breakdown of science as an integrated realm: The physicist, the biologist, the psychologist, and the social scientist are, so to speak, encapsulated in a private universe, and it is difficult to get word from one cocoon to another' (Von Bertalanffy, 1956: 6). He defined systems as

\footnotetext{
${ }^{2}$ From the UKFIET conference website.
} 
'complexes of elements standing in interaction' (ibid: 7) and set out to formulate principles which would be valid for all systems: 'developing principles running 'vertically' through the universes of the individual sciences, this theory brings us nearer to the goal of the unity of science' (ibid: 9). As Ackoff (1969: 332) later explained, 'we can define a system broadly and crudely as any entity, conceptual or physical, which consists of interdependent parts' - 'philosophical systems, number systems, communication systems, educational systems and weapon systems'. Since the 1960s, 'systems thinking' has grown in popularity, with the idea applied to areas as diverse as weather systems, city management, hospital administration and work groups (Cummings 1980).

Von Bertalanffy (1956: 9) made the important distinction between closed and open systems and emphasised that 'every living organism is essentially an open system'. An example of a closed or simple system might be a central heating system, 'controlled from the outside and based on linear causality' (Bates 2013: 40). By contrast, in an open or complex system, there are many agents and causality is complex and multidimensional. Doll (2008: 187) suggests that 'in simple terms, ones important for education, closed systems transfer and transmit, open systems transform.

Analogously, direct instruction, with its simplicity, would exemplify a closed systems approach while interpretive inquiry, with its complexity, would exemplify an open systems approach' (ibid). Within education, a systems approach looks not only at pedagogy and curriculum but at the entire structure of various elements - institutions and actors - and how they can best work together to achieve educational outcomes.

Since the 1970s, the influence of system theory has followed what Alhadeff-Jones (2008: 68) described as two 'epistemologically antagonistic' paths:

i) The first path 'allowed for the emergence of techniques reducing the complexity of the system to the study of its components and their relationships understood as objective phenomena' (ibid).

ii) The second tradition 'favoured a definition of complex systems by recognising the constructivist nature of modelling organisations as systems' (ibid) and focuses on the construction of shared meanings and participation.

Taking the second-order systems thinking approach, researchers have critically analysed how diverse educational goals are formulated, who decides them and whether and how they support and/or contradict each other. A focus on systems means primarily a focus on relationships, to explore the brokering, mediating and negotiating across various institutions (at times, with different agendas) and diverse actors within a single institution.

Within education, second-order systems thinking can be seen to have shifted attention from the individual and notions of 'deficit' (the dominant deficit discourse referred to by Aikman et al 2016) to consider systemic issues and problems. Rather than focusing on what skills and attributes the learner lacks and needs, discussion has turned to how educational systems might change through looking at, for instance, how collaborative leadership could lead to different kinds of goals being set. In Benathy's (1999) application of systems thinking to higher education, he analysed three levels of control and decision making - the governance level, the instructional level and learning level (how students experience learning). His analysis of who decides and who controls at the various levels and the rarity of finding a 'learning focused model' - demonstrates how systems theory can lead to a 
more bottom-up approach to thinking about 'how to provide for learning and human development' (ibid: 135).

So what are the limitations of systems thinking? There is much evidence that a first-order system thinking approach in education - promoting objective techniques and based on an assumption of universal standards and goals - has resulted in fragmented and dehumanising educational systems. In the context of English primary schools, Bates (2013: 50) argues strongly that 'children become 'statistics' related to outcomes rather than the recipients of improved education that the system is designed to produce... children are no longer viewed as the system's 'users', but as 'data' used to measure the effectiveness of the system'. She suggests that professionals are put in the position of 'servitude not service' (ibid) with decreasing autonomy. There is also little space for recognising multiple languages, knowledges or diversity of representations within this model, which assumes a simple linear relationship between educational inputs and outputs.

Many researchers have identified the consequences of systems thinking in education, relating these particularly to top-down management and standardisation of the curriculum. However, my concern in this paper is to shift from evaluating policy to explore what we may lose or gain conceptually. How can 'systems theory' limit the way we think about education and learning? Kinsella and Senior (2008: 659) suggest that 'the systems approach emphasises the mutuality of influence between the individual and the system and between the system and its environment'. However, they then go on to discuss 'environment' only in terms of the classroom environment and that of the school. The argument here seems to presuppose an organisation and an institution (the school, the classroom) which constructs or embodies 'the system'. So where does learning, knowledge and life outside the classroom come into this model?

Von Bertalanffy's idea was that 'organised wholes of any kind should be describable and to a certain extent explainable, by means of the same categories, and ultimately by the same formal apparatus' (Alhadeff-Jones 2008: 68). So does this imply a sense of closing down, of containing learning within categories - reliant on the notion of designed intervention, standardisation and predictable learning outcomes? Even Benathy's argument on systems thinking in higher education (which places the emphasis on learner experiences) is underpinned by assumptions of a planned learning path. How can we take account of spontaneous informal learning outside the system? In this sense, a systems approach in education could be considered to rely on the notion of exclusion and inclusion - the question is not just who is included or excluded - but what kind of learning processes and knowledges are included and privileged? Surely no educational system could or should embrace every kind of learning?

As President of BAICE, an association for comparative and international education, I am interested in how far comparative education is dependent on and has been shaped by systems thinking and this assumption of being able to find comparable categories of analysis. Laszlo (1972: 14) argued that the value of a general systems theory lay in the potential for comparison: 'Systems of various kinds can then be compared, their relationships within still larger systems defined, and general context established'. Well before this, Sadler argued that: 'The practical value of studying the working of foreign systems of education is that it will result in our being better fitted to study and to understand our own' (Sadler 1900, in Higginson 1979: 49). The starting premise of having similar educational 'categories and apparatus' in very different countries could be seen as the rationale for 
comparative educational studies - though as Crossley (2019: 181) argued in his BAICE Presidential Address 2018, 'context is another key concept in the history of our field' which challenges such notions of direct comparability of systems. However, the very meaning of 'system' seems to rely on some sense of boundedness and closure, which has been central within the discipline of comparative education - when education is compared across national borders - yet is increasingly problematic with the convergence of real and virtual worlds and globalisation. If we abandon systems thinking, would the field of comparative education disappear? So what are the implications of systems theory for the way that we think about inclusive education?

\section{Systems theory and inclusive education}

I used to go to school. I was even going to take Grade 8 exam... but I got fed up, sitting all day listening to Sir, staring at my books, wishing I was out with my friends. Then one day, my friend came from Addis. She said 'why don't you come back to town with us? Come to Bahir Dar, see the world, earn some money!' It was so tempting... I left, there and then. That was the end of school for me. I thought l'd have a great new life here. An agent helped me get this job as a maid and I started working in this big house... Now I really want to go to the night school. But I haven't started yet. I begged my boss to let me go. It's so difficult. I'm scared of walking in the dark alone. But I have to do it. I'm desperate to finish grade 8... get a job in an Arab country. I just need the grade 8 pass so I can go abroad, get a passport, escape from here...

[Abeba, a house-maid in Ethiopia] $]^{3}$

You can see what strong hopes Abeba still had for education, despite the terrible experiences she endured as a young girl trying to attend school. Even though school was free, she had had to juggle domestic chores with school attendance and face physical abuse from her family when she was forced into an early marriage. She was desperate to pass her grade 8 school exam so she could migrate. But even now as an adult, she faced similar problems - it is not easy for a live-in housemaid to start again at night school. From her story, we can begin to analyse the barriers she faced in accessing education and how policy makers could address these - this could be seen as the dominant approach to education, informed by 'systems' thinking. I will turn here to consider how systems thinking like this has shaped policy discourses on inclusive education, from the 1990 s to the present day.

This year marks the $25^{\text {th }}$ Anniversary of the World Conference on Special Needs Education, organised in 1994 by UNESCO and the Ministry of Education and Science of Spain. This led to the Salamanca Statement and Framework for Action on Special Needs Education - which endorsed the idea of inclusive education and has had a major influence on educational policies in countries across the world (Ainscow et al 2019). The Salamanca Statement on 'principles, policy and practice in special needs education' has been seen as a watershed moment, promoting the 'development of strategies that seek to bring about genuine equalisation of opportunity' (UNESCO 1995) and the concept of 'inclusive schools'. Rather than 'educational inclusion' referring only to students with disabilities,

\footnotetext{
${ }^{3}$ This is the first of five dramatic interludes which were performed at the conference by actors from the Mandala Theatre Company, directed by Yasmin Sidhwa. You can watch the full monologue here:

https://www.youtube.com/watch?v=Pq8PeHziMMc\&feature=youtu.be. In order to try to recreate the element of surprise and unease when actors jumped up from the audience at the conference, I have decided here too not to introduce these dramatic pieces in advance for the reader. This is in contrast to the usual more explicit 'signposting' and introductory contextualising of case studies in academic articles.
} 
the Salamanca report addressed all children 'whose conditions created a range of challenges to school systems'- including children from remote or nomadic populations, children from linguistic, ethnic or cultural minorities and street/working children (ibid). There was a significant shift from the earlier idea that students with disabilities needed expert knowledge in specialist institutions, to considering instead how disability had been socially constructed and could reflect structural inequalities (Slee and Allan 2001).

What had not changed, however, was the framing of inclusive education around systems theory, as these extracts from the second article of the Salamanca Statement illustrate:

'education systems should be designed and educational programmes implemented to take into account the wide diversity of these characteristics and needs'

'regular schools with this inclusive orientation are the most effective means of combating discriminatory attitudes, creating welcoming communities, building an inclusive society and achieving education for all' (UNESCO 1994, article 2)

Looking back to my discussion of systems thinking, these statements can be seen to connect with the aims of the first approach I outlined and are underpinned by assumptions about closed systems - with a search for 'techniques to reduce the complexity of the system to the study of its components' (Alhadeff-Jones, 2008: 68). The emphasis on 'regular schools' and 'educational systems' reinforces the idea in earlier policy statements, for instance in Education for All (UNESCO 1990), that education is synonymous with schooling, children and formal educational institutions. Whilst the Salamanca Statement points to the importance of schools learning to respond to diversity and taking a central role in building 'an inclusive society', there is no recognition here of learning and knowledge outside schools or of adult learning. Perhaps the remit of inclusive education had already become too large within the new concept proposed by the Salamanca statement to look beyond formal education systems and children? Or this may indicate the enduring appeal for politicians and policy makers of conceptualising education as a potentially 'closed' system with simpler solutions?

As Magnusson pointed out (2019: 681) there were significant tensions evident in the Salamanca document - for instance, around 'who is in focus' (whether to focus on Special Needs Education within inclusive education so that it was not overlooked) and the organisation of inclusion with regard to the notion of mainstreaming. He suggested that the 'malleability of inclusive education is not only a matter of local interpretations but also a matter of design' (ibid: 678). It is noticeable too that 'who is in focus' (ibid) rarely includes the adult or non-school youth population in such debates. Over the years, the concept of inclusion has become so broad - particularly when considering overlapping dimensions such as gender and disability - that policy makers have often preferred to concentrate instead on a narrower definition of inclusion as related to disability (UNESCO 2018).

This is not to suggest that 'inclusive education' has always been addressed in terms of a 'closed' or simple system - much research in this area analyses the complexity of factors influencing the proposed cultural changes around inclusion. Reflecting on papers in a Special Issue on the legacy of the Salamanca Statement, Ainscow et al (2019) emphasise that inclusion involves ideological positioning, rather than a simple technical 'fix': 
'... the promotion of inclusion is not simply a technical or organisational change - it is a movement in a clear philosophical direction. Moving to more inclusive ways of working therefore requires shifts in policy-makers' values and ways of thinking, which enables them to provide a vision shaping a culture of inclusion, through to significant changes within schools and classrooms. And, of course, this has to involve the wider community' (Ainscow et al: 676).

The call here to involve the 'wider community' appears to be for them to support cultural changes within schools and classrooms - rather than for providers to identify and respond to learning practices and priorities in the 'non-school' community. This idea that 'inclusive education is a process not an endpoint' (UNESCO 2018) has helped to shift the focus onto the pedagogical implications and potential for a more 'democratic' education for students. The factors influencing inclusion have been identified as flexible curricula and textbooks that do not promote stereotypes or bias, training teachers how to identify special needs, addressing systemic mechanisms of inclusion such as school fees and redesigning school buildings (ibid). Significantly, these elements are intended to help make a shift from 'integration' to 'inclusion' as a goal - recognising that all too often, the child is expected to change to fit the system, rather than the other way round.

Systems thinking has strongly shaped policy discourse on inclusive education - and has the potential to improve the quality of education provided for many marginalised groups, through schools becoming more welcoming places. But what about policy assumptions - including in the Salamanca Statement - that schools are the main (if not only?) way of addressing discrimination, changing attitudes and promoting new values in the wider society? Where does constructing and engaging with different knowledges and values in virtual and real worlds beyond the school gates come into this picture? Though there is recognition that 'community norms' need to be taken into account, this is often expressed in a negative sense: 'communities with discriminatory beliefs and attitudes can prevent learners from accessing educational opportunities' (UNESCO 2018: 7). Can the relationship between school and communities be seen in different terms from simply that of the providers and recipients of education? An interesting contrast lies in the literature on the concept of 'social exclusion' (see De Haan 2000), which focuses on adults rather than children and challenges the starting assumption in inclusive education that everyone necessarily wants to be included. What are the implications of systems thinking for questions around individual choice, voice and agency in education?

These are some of the questions that I will be exploring as I turn to alternative ways of thinking about inclusive education. I will now consider what happens when we take a different starting point from systems thinking for looking at inclusive education. ${ }^{4}$

\section{Inclusive education: thinking beyond systems}

i) Being a Woyto ${ }^{5}$

\footnotetext{
${ }^{4}$ Each dramatic interlude will be followed by an analysis, based first on systems theory, and then investigated through an alternative theoretical lens on inclusion.

${ }^{5}$ See the video of Mrs. Ansha's and Mr. Getenew's performance at

https://www.youtube.com/watch?v=2x6kkzaqnDA\&feature=youtu.be
} 
"Don't spend all your money in one day like a Woyto"

"She's quite pretty - if only she wasn't a Woyto"

"They've got tails... they came out of the lake... disgusting, eating hippo meat!"

We used to fight everyone who called us Woyto if any one of us was called Woyto. One day, I was walking along the street and a stranger came up. He was visiting our town. He asked me to show him where the Woyto live; he promised to give me birr, money, for showing me one. He asked "do the Woyto have tails? Is it true they have no arms and legs, and move like reptiles? What do they really look like?" I was so angry. I could hardly speak. I took him to a place near the bus station. There were several of our people who sit together and make baskets. I showed him. "You see we're not made up of tree barks. We're not some kind of water creatures. Just like you, Allah created us. We're just like you." He was ashamed and tried to calm me down. He gave me 300 birr.

But things are changing now. The young people don't get angry about being called Woyto. We have nothing to be ashamed of; so we don't care what others say about us. Now, I like the name Woyto. People call us so... but they are ignorant.

\section{Spoken by Mrs Ansha (a member of the Negede-Woyto community in Ethiopia)}

They're not interested in education. There's nothing we can do. In the local school there's such a high rate of absenteeism and dropout. The teachers and directors don't want to stay long in that school. It's too difficult. They fill in transfer forms as soon as they get there. They say "How can I discipline a Woyto child?" They're too wild. So different from us. When they're educated, reach a certain level and get a job, they don't identify themselves as Woyto. They don't go back to their community again.

\section{Spoken by Mr. Getenew (a local education official)}

We have just heard from Mrs. Ansha what it is like to be a Woyto in Ethiopia, to be despised by society and treated as sub-human. Even the school and the district education officer Mr. Getenew did not welcome them there. From a systems thinking perspective, we could consider how the school could adjust their usual structures to fit the Woyto children, perhaps operate a shift system or turn a blind eye to irregular attendance? At the time of the Derg regime in the $1970 \mathrm{~s}^{6}$, Government policy supported the Woyto community, giving them land and encouraging the children to go to school. But inside and outside school, there was still discrimination. Even the teachers made fun of them and still today they made Mrs Ansha's son clean all the toilets when she couldn't pay the school fees on time. Systems thinking may lead us to consider change, how schools can tackle this kind of social exclusion and make the Woyto children feel welcome in a safer environment. In an article on inclusive education, for instance, Ainscow and Sandhill (2010: 405) discuss research on the characteristics of schools with an 'inclusive culture', such as 'some degree of consensus amongst adults around values of respect for difference'. But can such cultural changes be initiated through an education system in isolation?

Let's take an alternative lens on this story - that of 'culture' and intercultural communication theory:

\footnotetext{
${ }^{6}$ The Derg, meaning 'committee' in Amharic and officially named the Provisional Military Government of Socialist Ethiopia, ruled Ethiopia from 1974 to 1987.
} 
'Terms of cultural engagement, whether antagonistic or affiliative, are produced performatively... the representation of difference must not be hastily read as the reflection of pre-given ethic or cultural traits set in the fixed tablet of tradition' (Babha 1994: 2).

Taking this concept of culture as performed (rather than 'pre-given') into the discussion of inclusive education can help us to explore the binaries of us/them in Mrs. Ansha's story. We can see the processes of 'othering' in society continue into school and even infuse the discourse of educational providers like Mr. Getenew. Mrs. Ansha described an event on the street, where she challenged the visitor's stereotyped ideas about Woyto people, and possibly provided a source of informal learning about his own prejudices. This is also inclusive education, but not in a school and it is not planned! Taking an intercultural lens can help us to 'understand how and when culture plays an active role in shaping and influencing our meaning-making endeavours' (Sarangi, 1995: 26) - and individual intercultural encounters like Mrs. Ansha described can be as significant as formal curricula. In her research in India, Singal (2019: 832) noted similar 'othering' processes when teachers described children with disabilities as a specific type of group, saying for instance: 'But God has gifted everyone with some quality. They might be different from us. They too have divya (divine) powers. That's why they are called divyang and I have felt this'. Learning to deconstruct stereotypes and recognise cultural othering in society are essential steps towards inclusive education. But can such learning processes be valued and promoted within a 'systems' approach?

Mrs. Ansha's account of how young people are now reclaiming their identities as Woyto - that they are even proud of their name - challenges the dominant idea of culture as static and essentialised. The notion in policy discourses of communities as resistant, as obstacles to education, is often built on an essentialised view of 'culture' as fixed, a barrier to progress or development (see Hofstede 1991). By contrast, Holliday (1999: 237) suggests that a "small culture" approach attempts to liberate "culture" from notions of ethnicity and nation'. For Mr. Getenew, success in formal education meant the chance to leave behind the Woyto cultural identity - an escape not only from poverty but also from their indigenous identity and cultural practices. But Mrs Ansha described a process of changing attitudes - again significantly taking place beyond formal education - where young people were joining together and taking pride in their name as Woyto, and conveying this to their elders. Yet this process of learning and empowerment seemed to be taking place despite rather than because of - the education system.

Moving away from a closed or the first approach to 'systems thinking' can enable us to explore how changes are taking place through informal learning and intercultural encounters outside formal institutions. Rather than starting from the question of how to include the Woyto in the education system, we can investigate processes of cultural essentialising and change. This raises questions about whose culture 'counts' and is valued in society (and schools), how cultural changes are taking place through informal and intergenerational learning (in this case, younger people seem to be challenging the established stereotypes of Woyto as 'something very bad and ugly'). Once we move away from closed systems thinking in particular, the assumption that schools are the most important way to initiate cultural change - such as promoting peace education materials to tackle tensions between different ethnic groups in areas of conflict - has to be revisited. The next section introduces my second alternative lens on inclusive education. 


\section{ii) A letter to the Minister of Education in Nepal}

Dear Government of Nepal Minister, Hasn't our constitution declared multilingual policies?

But today when I go into school, I only hear students being taught in English

Let me start by telling you the story of girl named Gyankumari

She lives in a village far away in the Far West of Nepal

With her hair neatly combed into two plaits,

she goes to a school 45 minutes walk away from her home

Gyankumari loves learning.

She is always the first one to enter the class

Even inside that stuffy classroom of grade 2, where five children share a bench, she loves being a student.

One day, Gyankumari's parents decide they should move to Kathmandu

They left with hopes of more money, better jobs and a stability that the Far Western states couldn't offer

There, Gyankumari was admitted to a community school

The school was recently declared an English medium school

Gyankumari spoke Hindi, Nepali and Tharu... but not English

My dear minister, I know you're wondering too.

Will Gyankumari lose her spark and love for learning?

My dear minister, Gyankumari is not alone

There are many Gyankumaris in Nepal

A child who has been speaking Tamang or Limbu all her life

And suddenly expected to learn in a language she's never spoken before.

Gyankumaris who can't join in or even follow what's going on in their classroom

But we need to start talking about them - now.

From a student

This letter gives a vivid insight into the issues faced by teachers and students in an education system where multilingualism is seen as a problem rather than a resource, and describes what happens when a top-down language policy is imposed on schools. How do teachers deal with a situation where children are unable to understand the language of instruction? The full letter (see video clip) relates how the teachers resorted to rote learning, getting students to chant in unison, and even fining anyone who spoke their mother tongue rather than English. Gyankumari struggled to retain her 'love of learning' when she could not see the relevance to her everyday life (as she did in the village) or even understand what is going on in the classroom. Maybe the school should adopt a bilingual or multilingual language policy, require teachers to take in-service training and develop an

\footnotetext{
${ }^{7}$ See the video clip at: https://www.youtube.com/watch?v=EKgu-G8vWqQ\&feature=youtu.be
} 
inclusive culture based on trust and respect rather than punishing students for speaking in their own language. These could all be responses from a systems perspective.

However, like the Woyto story, this letter brings up larger questions about whose knowledge and whose language counts most (in this case, English)? An 'ideological' model of literacy (Street 1984) draws attention to relationships of power, identity and inequality that are constructed around and through literacy and language. Recognising the dominance of 'schooled' literacy (i.e. literacy practices associated with formal educational institutions and programmes, often in official languages or English), Street (1993) proposed the concept of multiple literacies with differing values according to context and a continuum rather than a divide between orality and literacy. Building on these ideas, researchers and policy makers have developed a 'social practice' or 'situated' (Barton et al 2000) approach to literacy which recognises that throughout our lives we are all learning new literacy and oral practices, whether inside or outside a classroom. The notion of 'multiple literacies' draws attention to multilingualism and multimodality, providing a way of analysing diverse literacy practices, including indigenous literacy practices and digital communication.

When viewed through this lens, the issues around language and identity implicit in this letter can be seen to be embedded in and perpetuated through wider global relationships of power - beyond the school and classroom. Within Nepal, the Far West (where Gyankumari lived) is often regarded as the least developed or 'backward' region with few economic or educational opportunities (Mahat 2018). The story of Gyankumari's move is not just about changing school but also around different influences on education, as parents see languages of power - particularly English, but also Nepali in some contexts - as offering the chance for social mobility and migration. Though the education provided in Kathmandu was dull and incomprehensible to Gyankumari, her parents may have welcomed the chance to access an English medium education previously only possible in fee-paying private schools. Though this might be seen as the opposite to creating an inclusive educational culture - for Gyankumari's parents this could be a first step towards inclusion in an English-speaking community in Nepal, with the associated cultural and economic benefits. From a gender perspective, in Far Western Nepal, women are less likely to have learned English informally than men due to relatively limited mobility and fewer opportunities for formal work or migration. Participation in an English-medium school could be seen by many girls as a chance to catch up and as leading to empowerment in spheres beyond education.

Moving away from systems thinking can lead to investigating language and knowledge hierarchies within local communities and their relationship with formal education. Which languages are people (adults as well as children) learning, speaking and using in their everyday lives and how are their educational aspirations connected with language? For Gyankumari, the question of language was connected with knowledge too, and whether the knowledge and skills she learned outside school on her walk home, was valued or recognised in the classroom. How far is it only a question of bringing indigenous knowledge into the school curriculum - or rather about addressing broader power relationships between school and home? Could an 'open' systems approach promote different knowledges? 


\section{iii) A dialogue between women farmers in rural Philippines ${ }^{8}$}

Maring: Uy! Elna, Kamusta?

Elna: I'm okay! Just back from town. So where have you been?

Maring: Another training, in the council hall. I'm really interested in these seminars. There's so many ideas about how to earn money. New ideas... Like running a pig business.

Elna: Not pigs again...

Maring: I was thinking... if they give us a native pig, we could feed it just with leaves. We wouldn't have to buy any special feeds. So this seminar should be a good one. They said they'll give pigs to everyone who comes!

Elna: Pigs? Are those the same pigs they promised to give us last year?

Maring: That was a year ago and still not a pig in sight! They told us if the pigs of the first batch give birth, they'll give us our own pigs. My hubby spent two weeks digging up a hole near the toilet for our pig. But we still haven't got one...

Elna: You know what these trainings are like! They're full of promises.

Maring: We have to go anyway. If you're on benefits, there's no choice.

Elna: Waste of time then. We just sign our names, then go home. Come back in a few weeks' time. They tell us to start up a business and make it work.

Maring: I don't know... I wish they'd listen to us. Give us trainings we really need! Remember when we had a seminar on dish washing?

Elna: How could I forget it! As if 50 years of washing dishes isn't enough to make me a master dishwasher! That's when I thought I'd go for the camote chips instead. I just copied what they showed us! There wasn't any real training. They just showed us and we had to copy it. I bought 10 kilos of camote (sweet potato) from my brother-in-law. Then I copied what they taught us the next day.

Maring: And did it work?

Elna: They told us we can sell each pack of chips for four pesos. Then when our business grows, we can even sell them in another country. The trainer... he was someone from our place. When we asked questions, he didn't answer. I think he didn't want to let on what was in the chips

\section{Francisca, a social worker working with the women:}

I always wanted to be a social worker. We grew up poor too. That's why I'm a social worker. Now I'm in charge of the training and education section. Trainings for women farmers. Like our Family Development session. Training every month... on important things, like knowing yourself, managing stress, managing their money. Different things. I like it but it's not easy. They're always asking for capital. They're not interested in anything else. They have learn to stand on their own two feet. We're here to help them, but we can't give everything. You can see they just come for the 500 pesos. They're there but not listening. They just want to get rich quickly.

Elna and Maring, two farmers in the Philippines, did not think much of the training they were given by local government. Here they were talking about inclusion and 'systems' for adult vocational training, rather than children's schooling - but are the issues any different? Like Gyankumari, Elna

${ }^{8}$ https://www.youtube.com/watch?v=PQ3hlwkHOWk\&feature=youtu.be 
and Maring did not find this kind of education useful. They say it's not 'real training', just demonstrating how to make camote chips without any hands-on guided activity. More importantly, no one had ever asked them what sort of training they would like nor recognised how precarious their livelihoods were, renting land, lacking capital to set up a new business. From a systems thinking perspective, the programme was unsuccessful because it was not designed around women's needs and situations - they lacked monetary support and there was no consideration of the resources they would need to make a successful business.

We can see the gap between Elna and Maring, and the social worker, Francisca. Although Francisca was from a similar background originally, she was now in the role of 'provider' and the hierarchical relationship can be seen as similar to that of teacher/student in school. What is striking here is the us/them discourse - in the way the women talked about the trainer, but also how the trainer talked about the trainees. She dismisses the women's concerns as always wanting to get money rather than training. She believed she knew what kind of training they needed - soft skills like 'knowing yourself'. This seems to be an example of a top-down approach to providing vocational training within a rigid system which does not have space to adapt to women's needs and aspirations. What comes across too is the commodification and ritualisation of training here - a perspective shared by Francisca and the two farmers. I have seen and heard so many participants elsewhere in the world discussing training programmes in similar terms of what allowances/financial benefits are offered (including in Nepal (see Robinson-Pant 2001) and during ethnographic fieldwork in Kapilbastu district this year).

Let's take the lens of informal learning to look at this situation. Informal learning has been defined as resulting 'from daily life activities related to work, family or leisure. It is not structured (in terms of learning objectives, learning time or learning support) and typically does not lead to certification. Informal learning may be intentional but in most cases it is non-intentional (or 'incidental'/random)' (EU 2001, as cited in Colley et al 2003: p 25). It can however be problematic to think of informal, formal and non-formal learning as discrete categories and disregard, for instance, informal learning that takes place in formal schools (particularly the hidden curriculum). Informal and formal learning can be conceptualised as 'lying on a continuum ranging from accidental/incidental learning, through task-conscious learning, through self-directed learning to non-formal and formal learning' (Rogers 2014: 5). The training that Elna and Maring described can also be seen as involving formal, nonformal and informal learning.

As adults, we often learn new skills and knowledge informally - if we want to learn how to use a new App on our phone, we might ask a friend, read about it online, mess around ourselves, but we are unlikely to sign up for a course. This is exactly the process that Elna described when she tried to make the camote chips after the seminar. She did not find the trainer's idea of leaving it in the sun worked, so she experimented and found she had to fry them straightaway. Her criticism of the trainer was partly that he did not answer their questions and he ran the session in a more formal way, just demonstrating the technique for them to copy like school students. 'Training' here can be seen to be shaped by the formal education sector - adult women are put in the position of students in a classroom, the topics and session structures are pre-determined. From Elna and Maring's frustration at not being allowed to ask questions, it seemed as if the interaction in the camote seminar is similar to that of a school classroom with the trainer positioned hierarchically as 'expert'. Inclusive education here related not to whether or not the women could come to the training - they 
had to - but whether the trainer recognised and built on their current informal learning and 'funds of knowledge' (Moll et al 1992) in farming and running agricultural businesses.

Moving away from a 'closed' systems thinking approach on the training programme to consider informal and everyday learning practices, providers could start with women's current livelihood activities and the ways in which they gained those skills (such as marketing vegetables and sharing ideas with each other, as Elna and Maring do here). The questions that arise are not just 'what should they learn?' but 'how can they learn best?' Researchers have found that individualised and holistic support (including access to capital) is an effective approach to practise agricultural extension (Rogers, 1993, Robinson-Pant 2016) - starting with a livelihood activity, such as rearing pigs, and teaching literacy or numeracy skills as and when they are needed ('embedded' skills development). Exploring informal learning - the 'trial and error' approach that Elna described here can provide an alternative to analysing how to integrate indigenous knowledge and skills into a preplanned curriculum.

\section{iv) The story of a housemaid in Bahir Dar, Ethiopia9}

\section{Hirut}

I've always wanted to go to school. Back then, people used to say, 'what's the point of educating girls?' It wasn't normal for us to go to school. Mum didn't go to school, so I didn't go either. My mum died when I was 11. So I came to live with her sister here. That's when I started working. She didn't have enough for herself, let alone me. So I started work on a building site.

I was an assistant plasterer and mason. There was a lot of work there.... very hard work, exhausting. Once I saw a lady on the building site giving out tools, registering everyone. She didn't do any hard work. No one touched her; no one harassed her. I thought if I'd got grade 10 exam, I could work like her. So I joined the night school.

It's so hard if you've never been to school. It's not easy. Studying at night. Lifting cement all day and then school every night... I used to fall asleep in the class. I was so hungry and tired. I didn't understand much what was going on and the teachers made fun of me. "Wake up! Don't you come here to learn? Why are you asleep?" Then the whole class used to laugh at me. I left the night school at grade 4. Even then I didn't learn to read and write; I only learnt the numbers.

I feel annoyed I'm not educated. It's embarrassing. When men ask me out, I'm ashamed to say I've never been to school. Once, an educated man working in a government office asked me to get married. I said no. I thought he'd hate me once he found out.... if one day he got angry and called me "uneducated, illiterate, and denkoro, deaf, stupid". But three months ago, you wouldn't believe it, I got married. My husband is grade 10. I told him straightaway I hadn't been to school. He just said 'it's not a problem. The main thing is what you're like; not whether you've been to school or not".

\footnotetext{
${ }^{9}$ https://www.youtube.com/watch?v=6zwqHOtWWMo\&feature=youtu.be
} 
What strong hopes Hirut had for education! We heard how she was unable to go to school as a child and now as an adult (just like Abeba earlier), it was just as hard to attend night school. But for them both, education and formal certificates offer an escape from abuse, poverty, and even being looked down on because they are illiterate. Hirut envied the educated women who no longer had to do manual labour or work as housemaids.

From a systems thinking perspective, we could ask how the educational system could better support women like Hirut to continue their studies. We could also consider how both work and the adult education on offer perpetuated gendered relationships of oppression. Hirut had suffered from abuse in her workplace and had little control over her life. When she managed to attend the night school, she found such an unwelcoming atmosphere and was spoken to as if she was a child. The teachercentred approach seemed very similar to a school classroom. However this time, she was determined to get through the course, believing so strongly that educational qualifications would offer a gateway to new opportunities.

But this story is more than an example of exclusion from an educational system. As with the farmers in the Philippines, we can take the lens of informal learning and situated literacy to look at the skills and knowledge that Hirut learned informally in order to survive. She described the challenges of not having functional literacy skills - getting her friends to help when she had to keep records of expenses in the house where she worked. The stigma and shame of being called 'denkora', an Amharic word that means 'deaf and stupid' and often used to ridicule nonliterate people, stopped her telling her employers that she could not read and write. But she learned to use her mobile phone through recognising the numbers and using them to record contacts. Her friends helped her to do this. So, literacy for Hirut was also about peer learning, learning to do something when she needed to, rather than sitting in a classroom. But the night school offered a chance to go beyond that - as literacy was also about the status of being educated, and her own identity, even who she felt she could marry. By looking at what literacy meant in this community - beyond the functional aspects of keeping accounts or replying to texts - we can understand more about why Hirut would go to such lengths to access formal learning. Though Hirut had learned to use a mobile phone through sitting with her friends, she aspired to the symbolic value of literacy as schooling.

Looking at the story through the lens of literacy as social practice involves exploring the meanings of literacy for women like Hirut, and the differing values of different literacy practices (mobile phone texting, writing school exams, keeping accounts, filling in bank forms) in this specific society. The most immediate policy questions might be 'how can women who missed out on schooling best learn to read and write or catch up on the exams they missed? Is night school the best place?' However, taking into account relationships of power and the symbolic aspects of literacy, the question of how best to learn functional literacy skills seems too limited and overlooks issues around identity and social change. We can also consider the broader question of what are the policy implications of changing literacies - including the increasing use of digital literacies - for everyone in this community?'

\section{Inclusion beyond the school gates}

These questions about educational inclusion and understanding the aspirations of young people arise not just in Ethiopia or Nepal or the Philippines. The final performance in my plenary lecture was 
a podcast by Tachia, who lives on a London housing estate and took us powerfully into how he saw the world he came from, bleak, violent, dark ${ }^{10}$... Excluded from mainstream education, he was based in what is called a PRU (Pupil Referral Unit). His story raised the question of how schools can respond to young people with such different lives. All too often, the response is to treat them all the same, a one-size-fits-all approach. At first glance, Tachia's story seemed such a contrast with Abeba and the other young women in Ethiopia or Nepal who were desperate to be in formal education. Maybe the barriers to education in the UK are not as visible as in Ethiopia or Nepal. But some issues are actually very similar - young people did not feel the schools were listening to them or supporting them and they had little or no voice in how 'the system' worked.

These stories - based on real experiences in Ethiopia, Nepal, the Philippines and the UK - raise questions about inclusive education, which are vitally important to address. How can the hurdles faced by young girls trying to go to school, whether family opposition, distance, peer pressure or physical and sexual abuse, be overcome? How can a welcoming educational environment for all students be created? How can we ensure that educational programmes for adult women relate to their lives and lead to better livelihood opportunities? These questions are not new and have been asked over many decades - but the answers to these questions seem to lie far beyond the educational system. So perhaps we now need to move beyond 'systems thinking' - particularly closed systems thinking - with its default position of school or formal educational institutions as providing the solutions. By seeking out or even imposing some measure of uniformity on what are highly diverse situations, systems thinking can discourage attempts to respond to diversity.

I began this paper by looking at the limitations of systems thinking as it has been conceived in relation to inclusive education - particularly the implicit assumption in policy that schools are the major vehicle to address discrimination, change attitudes and promote new values in the wider society. The stories illustrated that taking a systems lens can only take us so far: we can look at how to improve the formal education system through focusing on the relationships within the institutions involved and their goals or philosophy. However, we need to understand wider social and cultural practices that influence what goes on in school and training programmes - particularly teachers' and students' beliefs and interactions. I looked at how intercultural communication theory and an ideological model of literacy as a social practice can provide valuable resources for investigating processes of cultural change. Why do some parents (and schools) want children like Gyankumari to learn in English, a completely unfamiliar language, at all costs? What is the meaning of 'literacy' or 'training' in Elna's or Hirut's everyday lives? How have women learned to use mobile phones or managed to find jobs abroad without ever having learned to read and write formally? Unlike closed systems thinking which tends to promote a 'school first' approach, our starting point then becomes life and all that happens outside (and within) school. To use the anthropologist Brian Street's words, first we need to ask 'what's going on here?' - before we turn our attention to how the educational system might fix it. This has been the starting point for many ethnographers in the field of comparative and international education, though the pressing challenge still remains around how to use ethnographic data more effectively to inform policy processes and goals (Robinson-Pant 2008).

\footnotetext{
${ }^{10}$ The video clip or script cannot be included here as it was commissioned by the Mandala Theatre Company for another purpose.
} 
Whilst cultural stereotypes can be challenged in school textbooks and curricula, teachers and students may still hold the same beliefs. Inclusive education cannot rely on formal institutions alone to initiate changes in social and cultural attitudes. As the story of Mrs. Ansha from the Woyto community illustrated, informal learning through everyday encounters, social media and schools also shapes beliefs. For too long, development discourses have positioned 'the community' as outside education - debates about community participation are premised on the idea that communities are somehow not participating in development (or learning) already. Within inclusive education debates too, the emphasis is on how to mobilise or convince communities to support the changes needed in schools. All the stories in this paper - whether from the Philippines, Nepal, Ethiopia or the UK shared a polarised view of 'us' and 'them', educational providers and communities as recipients. The greatest challenge for all of us is how to transform this hierarchical relationship between educational institutions and communities. Moving beyond closed systems thinking could be an important first step.

\section{Endnote}

At this point of the plenary lecture, I took the audience behind the scenes for a glimpse of how the presentation had emerged. This was a collaborative project - and a venture into new ways of exploring inclusive education and learning, particularly through creative approaches to storytelling all of which are difficult to recreate in this journal article ${ }^{11}$.

The process began early in 2019 with teams in Ethiopia, Nepal, UK and the Philippines (all partners in the University of East Anglia UNESCO Chair for Adult Literacy and Learning for Social Transformation) exploring our own understanding of inclusive education systems. We began to discuss what 'inclusion' means in these very different contexts, supported by a literature review by Chris Millora. Each country team then designed a project to explore ideas about educational inclusion with different communities: Amina Singh and Yukta Bajracharya ran a creative writing workshop with teachers and educationalists in Kathmandu with the NGO Word Warriors (resulting in the 'letter to the Minister of Education'); Gina Lontoc and colleagues from the University of Santo Tomas facilitated a world cafe with women farmers in San Jose, Nueva Ecija to produce a documentary (see the dialogue between Elna and Maring); Turuwark Warkineh and Abiy Menkir Gizaw facilitated discussions with communities and educational providers in Bahir Dar (leading to the stories about Mrs Ansha and the two housemaids). We were excited to discover that Yasmin Sidhwa, Director of the Mandala Theatre Company, had been working on very similar issues around exclusion in the UK context, running drama workshops with young people in pupil referral units which looked at 'what makes you want to learn?' 'What makes you feel like a failure?' The final performance in the lecture was part of a play written by Avaes Mohammad for Mandala Theatre Company, called 'Pipeline'. The dramatic interludes were performed at the UKFIET conference (see the video extracts in this article) by Theo Laird, Anusha Abbas and Nelvin Kiratu, directed by Yasmin Sidhwa.

\footnotetext{
${ }^{11}$ You might see this endnote in terms of the usual 'methodology' section of a journal article, though it should be noted that the dramatic material are fictionalised dialogues and monologues and are not intended to be treated as empirical 'data'. In order to mirror the structure of my lecture, I decided not to follow the academic convention of placing this section near the beginning of the article. As one member of the audience commented, this was the 'reveal all' moment at the end of the lecture.
} 


\section{Acknowledgements:}

In addition to all of the above, I would like to thank the following people for insightful comments on this paper: Dr. Agnieszka Bates, Dr. Roger Robinson, Prof. Alan Rogers and Prof. Nidhi Singal. BAICE funded this initiative and the plenary performance would not have been possible without the support of Dr. Malcom Mercer, Sarah Jeffrey and the BAICE Executive Committee. An anonymous peer reviewer from Compare gave useful feedback on how this worked (or not) as a written text.

\section{References}

Ackoff, R. (1960) Systems, organisations and interdisciplinary research, reprinted in Emery, F. (ed) Systems Thinking: Selected Readings, Harmondsworth: Penguin

Aikman, S., Robinson-Pant, A., McGrath, S., Jere, C., Cheffy, I., Themelis, S., Rogers, A. (2016) Challenging deficit discourses in international education and development in Compare: a journal of comparative and international education 46, pp. 314-334

Ainscow, M. and A. Sandill (2010) Developing Inclusive Education Systems : The Role of Organisational Cultures and Leadership. International Journal of Inclusive Education 14(4): 401-16.

Ainscow, M., Slee, R. and M. Best (2019) Editorial: the Salamanca Statement: 25 years on, International Journal of Inclusive Education 14 (4): 671-676

Alhadeff-Jones, M. (2008) Three generations of complexity theories: nuances and ambiguities, in Mason, M. (ed) Complexity Theory and the Philosophy of Education, Oxford: Wiley-Blackwell

Bhabha, H. (1994) The Location of Culture, London: Routledge

Bacchi, C. (1999) Women, Policy and Politics. The Construction of Policy Problems, London: Sage Publications

Banathy, B. (1999) Systems Thinking in Higher Education: Learning Comes to Focus. Systems Research and Behavioral Science 16:133-45.

Barton, D., Hamilton, M. and R. Ivanic (2000) Situated Literacies: Reading and Writing in Context, London: Routledge

Bates, A. (2013) Transcending Systems Thinking in Education Reform : Implications for PolicyMakers and School Leaders. Journal of Education Policy 28(1):38-54.

Colley, H., Hodkinson P. and J. Malcom (2003) Informality and formality in learning, Report for the Learning and Skills Research Centre, Leeds: University of Leeds, available at: http://www.LSRC.ac.uk Crossley, M. (2019) Policy transfer, sustainable development and the contexts of education, Compare, Vol. 49, No. 2, 175-191 https://doi.org/10.1080/03057925.2018.1558811 
Cummings, T. (1980) Preface, Systems Theory for Organization Development, Chichester: John Wiley and Sons

De Haan, A. (2000) Debates on social exclusion in the South: What have they contributed to our understanding of deprivation? Uppingham Seminar Background Paper, http://www.uppinghamseminars.co.uk/background2001.pdf

Doll, W. (2008) Complexity and the culture of curriculum, in Mason, M. (ed) Complexity theory and the philosophy of education, Oxford: Wiley-Blackwell

European Commission (2001) Making a European Area of Lifelong Learning a Reality, Brussels: EC

Hofstede, G. (1991) Culture and Organisations: Software of the Mind, London: McGraw-Hill

Holliday, A. (1999) Small Cultures, Applied Linguistics, 20, 237-264

Kinsella, W. and J. Senior (2008) Developing Inclusive Schools: A Systemic Approach. International Journal of Inclusive Education 12(5-6):651-65.

Laszlo, E. (1972) The Systems View of the World, Oxford: Blackwell

Magnusson, G. (2019) An amalgam of ideals - images of inclusion in the Salamanca Statement, International Journal of Inclusive Education, 23: 7-8, 677-690

Mahat, Jaya Jung (2018) Karnali 2.0 accessed at: https://kathmandupost.com/opinion/2018/01/28/karnali-20

Moll, L., Amanti, C., Neff, D. \& N. Gonzalez (1992) Funds of knowledge for teaching: using a qualitative approach to connect homes and classrooms, Theory into Practice, 31(2), 132-141

Robinson-Pant, A. (2001) Why eat green cucumber at the time of dying? Exploring the link between women's literacy and development: a Nepal perspective, UNESCO Institute for Education, Hamburg, ISBN 92820 1107-0, 198 pp. Available at: www.unesco.org/education/uie/pdf/robinson-pant

Robinson-Pant, A. (2008) "Why literacy matters": exploring a policy perspective on literacy, identity and social change, Journal of Development Studies, Vol. 44, No. 6 July, pp $779-796$

Robinson-Pant, A. (2016) Learning Knowledge and Skills for Agriculture to Improve Rural Livelihoods, IFAD-UNESCO, Paris. Available at: http://unesdoc.unesco.org/images/0024/002457/245765E.pdf

Rogers, A. (1993) Adult education and agricultural extension: some comparisons, International Journal of Lifelong Education, Vol. 12/3, 165-176

Rogers, A. (2014) The Classroom and the Everyday: The Importance of Informal Learning for Formal Learning, in Investigar Em Educacao Vol 1, no 1, 2014 pp 7-34

Sadler, M. (1900) How far can we learn anything of practical value from the study of foreign systems of education? Quoted in Higginson, J. (ed) (1979) Selections from Michael Sadler: Studies in World Citizenship, Liverpool: Dejall and Meyorre 
Sarangi, S. (1995) Culture, in Verschueren J. et al (eds), Handbook of Pragmatics, Amsterdam: John Benjamins

Singal, N. (2019) Challenges and opportunities in efforts towards inclusive education: reflections from India, International Journal of Inclusive Education, 23:7-8, 827-840, DOI:

$10.1080 / 13603116.2019 .1624845$

Slee, R. \& J. Allan (2001) Excluding the included: A reconsideration of inclusive education, International Studies in Sociology of Education, 11:2, 173-192, DOI:

10.1080/09620210100200073

Street, B.V. (1984) Literacy in Theory and Practice, Cambridge: Cambridge University Press

Street, B.V. (1993) Cross-cultural Approaches to Literacy, Cambridge: Cambridge University Press

UNESCO (1990) World Declaration on Education for All and Framework for action to meet Basic Learning Needs, adopted by the World Conference on Education For All, Jomtien, Thailand, 5 9 March 1990, Paris: UNESCO

UNESCO (1994) The Salamanca statement and framework for action on special needs education, adopted by the world conference on special needs education: access and quality, Salamanca, Spain, 7-10 June 1994

UNESCO (2018) Concept note for the 2020 Global Education Monitoring Report on inclusion, Paris: UNESCO, https://unesdoc.unesco.org/ark:/48223/pf0000265329

Von Bertalanffy, L. (1956) General System Theory, reprinted in Ruben, B. \& J. Kim (eds) (1975) General Systems Theory and Human Communication, New Jersey: Hayden Book Company Inc 